\title{
Prevalence of depression among people with type 2 diabetes mellitus: a cross sectional study in Palestine
}

\author{
Waleed M Sweileh ${ }^{*}$, Hanadi M Abu-Hadeed ${ }^{2}$, Samah W Al-Jabi ${ }^{3}$ and Sa'ed H Zyoud ${ }^{1}$
}

\begin{abstract}
Background: Diabetes mellitus is a common chronic metabolic disorder and one of the main causes of death in Palestine. Palestinians are continuously living under stressful economic and military conditions which make them psychologically vulnerable. The purpose of this study was to investigate the prevalence of depression among type II diabetic patients and to examine the relationship between depression and socio-demographic factors, clinical factors, and glycemic control.

Methods: This was a cross-sectional study at Al-Makhfiah primary healthcare center, Nablus, Palestine. Two hundred and ninety-four patients were surveyed for the presence of depressive symptoms using Beck Depression Inventory (BDI-II) scale. Patients' records were reviewed to obtain data pertaining to age, sex, marital status, Body Mass Index (BMI), level of education, smoking status, duration of diabetes mellitus, glycemic control using $\mathrm{HbA1C}$ test, use of insulin, and presence of additional illnesses. Patients' medication adherence was assessed using the 8-item Morisky Medication Adherence Scale (MMAS-8).
\end{abstract}

Results: One hundred and sixty four patients (55.8\%) of the total sample were females and 216 (73.5\%) were < 65 years old. One hundred and twenty patients (40.2\%) scored $\geq 16$ on BDI-II scale. Statistical significant association was found between high BDI-II score ( $\geq 16)$ and female gender, low educational level, having no current job, having multiple additional illnesses, low medication adherence and obesity (BMI $\geq 30 \mathrm{~kg} / \mathrm{m} 2)$. No significant association between BDI score and glycemic control, duration of diabetes, and other socio-demographic factors was found. Multivatriate analysis showed that low educational level, having no current job, having multiple additional illnesses and low medication adherence were significantly associated with high BDI-II scores.

Conclusion: Prevalence of depression found in our study was higher than that reported in other countries. Although $40 \%$ of the screened patients were potential cases of depression, none were being treated with anti-depressants. Psychosocial assessment should be part of routine clinical evaluation of these patients at primary healthcare clinics to improve quality of life and decrease adverse outcomes among diabetic patients.

Keywords: Diabetes mellitus, Depression, Palestine

\section{Background}

Diabetes mellitus (DM) is a common health problem with serious medical and economic consequences. Between 2010 and 2030, there will be a 69\% increase in numbers of adults with diabetes in developing countries and a $20 \%$ increase in developed countries [1]. The Arab

\footnotetext{
*Correspondence: waleedsweileh@yahoo.com

'Department of Pharmacology/ Toxicology, College of Medicine and Health Sciences, An-Najah National University, Nablus, Palestine

Full list of author information is available at the end of the article
}

world (North Africa, Middle East, and Gulf area) will have second highest increase in percentage of people with DM in 2030 compared to other parts of the world [1]. Few studies about prevalence of DM were carried out in Palestine and showed a higher rate of this disease in an urban community than in a rural community [2-4]. However, no reliable data exist for treatment, complications, economic effect, and outcomes of treatment of DM in Palestine [5].

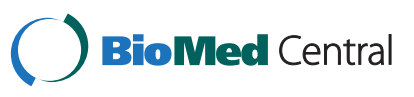


Depression is another prevalent condition. Approximately 340 million people worldwide suffer from depression at any given time [6]. A study designed to examine the prevalence of mood disorders in 14 countries found that the 12-month prevalence of mood disorders was lowest in Nigeria and highest in the United States [7]. It was estimated that depressive disorders were the fourth leading cause of disease burden in women and seventh leading cause in men [8,9]. Major depression was found to be the second leading cause of disability-adjusted life years (DALYs) lost in women and the tenth leading cause of DALYs in men [10]. In Palestine, psychological distress is high, quality of life is very low, and daily life of Palestinians is constantly under threat which make Palestinians more vulnerable to stress and depression [5].

Relationship between DM and depression has been investigated by many researchers. Prevalence of depression among individuals with DM appears to vary by type of DM, race/ethnicity, and among developed and developing nations $[11,12]$. Therefore, screening for depression among diabetic patients is important in different races and ethnicities. Actually, studies indicated that about $49 \%$ of the diabetic patients having severe depression were misrecognized on the primary healthcare clinics $[13,14]$. Unfortunately, Palestinians with chronic diseases are usually less likely to have regular sources of medical care for screening or preventive services [15].

The aim of this study was to estimate the prevalence of depression among Palestinian type 2 diabetic patients attending primary healthcare settings and to describe sociodemographic and clinical characteristics associated with diabetic patients having depression. Given the scarcity of research about depression among Palestinians in general and among diabetic patients in particular, such study is needed. The knowledge gained from this study will assist healthcare practitioners to better understand depression in diabetes mellitus and design treatments that address the psychological and the metabolic needs of affected individuals to improve overall health outcomes.

\section{Methods}

\section{Setting and design}

This was a cross-sectional descriptive study for the purpose of evaluating the presence of depression symptoms and their association with glycemic control (HbA1C), medication adherence, clinical and demographic variables among Palestinians with type 2 diabetes mellitus.

Nablus is the largest city in north West-Bank of Palestine. Residents of Nablus city are predominantly Arabs. The study was carried out at the governmental diabetes primary healthcare clinic (Al-Makhfia) in Nablus city. There are five main healthcare providers of health services in Palestine: Ministry of health, UNRWA, NGOs, Palestinian Military Medical Services (PMMS) and Private for profit. $\mathrm{MOH}$ bears the heaviest burden, as it has the major responsibility [16]. During the study period, the investigator visited the primary healthcare center at AlMakhfia, Nablus. The visits were made on Sundays, Tuesdays, Wednesdays and Thursdays every week. These are the assigned days for diabetic clinics to deliver care for patients with type II DM. Al-Makhfia center is the only governmental center that provides care for diabetic patients with governmental insurance in Nablus city. The study was carried out from April to August 2012.

\section{Sample population}

This study included a convenience sample of adult population. Participants were recruited from Al-Makhfia diabetic clinics while waiting to be seen by their health care providers. The inclusion criteria for this study were: 1) males and females 18 years old and older who selfreport being diagnosed with type 2 diabetes by a health care provider and has a medical file at the diabetic clinic; 2) self-report type 2 diabetes for one year or longer; 3) under medical care for diabetes treatment according to $\mathrm{MOH}$ documents; 4) able to understand the questions in order to help complete forms and questionnaires; 5) willingness to participate in this study and finally 6) being scheduled to do HbA1c at the laboratory of $\mathrm{MOH}$ at the time of the visit. The exclusion criteria were based on self-report of the following: 1) physical and or mental conditions that interfere with participation, and 2) inability to obtain venous blood sample.

\section{Sample size}

No studies about the prevalence of depression among diabetic patients in Palestine have been reported. Therefore, we estimated the sample size based on studies in other Arab countries [17]. The sample size was estimated based on the following assumptions: a descriptive study with dichotomous outcome: the sample size tables shows that a sample of 246 participants is needed if we assume the prevalence of depression to be $20 \%$ and the width of confidence interval to be $10 \%$ and the confidence limit to be $95 \%$.

\section{Participant recruitment procedure}

The investigators obtained written approval from $\mathrm{MOH}$ to carry out this study. A brief screening for recruitment of participants was conducted by the investigators to identify potential participants in the following manner: every person in the waiting area was asked if he is willing to talk to the investigator. If the person agreed to talk to the investigator for possible participation, the attending specialist was asked if that person is scheduled to do HbA1c at that visit. If the person who agreed was scheduled to do HbA1c, then an informed consent was read and obtained by the investigators at the diabetic 
clinic. Once the consent was signed, verification of inclusion and exclusion criteria took place. The questionnaires required for the study were presented and explained for its completion during this session. The forms and questionnaires that were completed included: 1) demographic and clinical questionnaire to gain information on participant, 2) BDI-II to measure depressive symptoms), Morisky Medication Adherence Scale (MMAS-8) to determine level of medication adherence among participants.

An investigator, who is a graduate nursing student with a long experience in nursing, was trained prior to initiation of the study to assist in the recruitment and administration of questionnaires. Re-training of the investigator who administered the questionnaire took place after the first week of the research study based on the need to clarify certain points in the questionnaire. All participants completed the questionnaires in a private area in the clinic. A venous blood test, in a non-fasting state, was drawn for measuring the $\mathrm{HbA1C}$ during the same session. A certified phlebotomist was available on site to obtain the sample and forward it to official labs of the $\mathrm{MOH}$. Results regarding $\mathrm{HbA1c}$ for each participant were available to the PI within the same working day. Data collection and the completion of questionnaires took place before HbA1c test. A note was given to healthcare provider in the clinic about each participant's HbA1c results.

\section{Instruments}

\section{Measure of depression symptoms}

The presence of depression symptoms was evaluated using the Beck Depression Inventory-Second Edition (BDI-II) [18]. Beck Depression Inventory is a wellknown self-report instrument. Its original version (21 items) was introduced in 1961 and its reliability and validity have been established across a broad spectrum of clinical and non-clinical populations [19-25]. The BDI-II is available in English and has been translated into Arabic and validated for use to measure depression. The BDI-II has been translated into Arabic and validated for use to measure depression. Use Permission to use the Arabic version of BDI-II was obtained from the author who did the translation and validation [26,27].

The term "depression" in this study referred to the self-report of depressive symptoms identified in the BDIII. The format of the BDI-II test is for the participants to select and circle the number beside one of the four phrases listed that best describes their state in the past two weeks including the day the questionnaire is answered. The instrument consists of 21-items/statements that are self-reported and takes approximately $15 \mathrm{mi}-$ nutes to complete. The score ranges from 0 - 63 to determine possible degree of depression symptoms. The instrument developers established four groups of scores and classified as the following: "minimal 0-13, mild 14-
19, moderate 20-28, and severe 29-63" [18]. Scores provide an estimate of the overall symptom severity of depression. High scores indicate greater depressive symptoms. We used the most commonly used cut-off scores for BDI of $\geq$ 16 to indicate clinical depression [28]. It should be emphasized that high BDI II scores presented in this study are not definitive diagnosis of depression. Rather, high scores are indicative of the presence of depressive symptoms and further clinical consultation to establish definitive diagnosis of depression is needed.

\section{Serum glycated hemoglobin measure (HbA1C)}

Glycated hemoglobin (HbA1c) is used to measure blood glucose control over several months and provides an estimate of how well diabetes has been controlled over the last 2 or 3 months. It is the goal standard of care for determining potential risk for developing problems, such as retinopathy, renal disease, cardiovascular disease, peripheral neuropathy or stroke. Potential complications are especially true if $\mathrm{HbA} 1 \mathrm{C}$ remains high for a long period of time [29]. The goal for HbA1C in adults is < 7\% [29]. Serum blood test for HbA1C was obtained on the same day and in the same clinic site either before or immediately after completing the questionnaires depending on time available in clinic. The blood sample was obtained by venous puncture drawn by a certified phlebotomist and sent to a designated local laboratory with coded identification number. HbAlc determination for all samples was done in the same laboratory by the same technician and applying the same technique. The method used to determine HbA1c is NycoCard READER II, using the Boronate affinity test principle. It is NGSP-certified method.

\section{Medication adherence}

Anti-diabetic Medication adherence was measured using Morisky Medication Adherence Scale (MMAS-8) [30]. Approval to use and translate the MMAS-8 into Arabic language was obtained from the developer. The translation was carried out according to standard forward and backward method. The Arabic- translated version of MMAS-8 was used in previous publication [31]. The MMAS- 8 is an eight items questionnaire designed to measure medication adherence. It is composed of seven Yes/No questions. Details of the Arabic translation and its use were described previously [31]. The eighth question is a 5-points likert scale. In this study, patients with a total score of MMAS- 8 less than 6 are considered to have poor medication adherence.

\section{Demographic and health questionnaire}

A questionnaire was designed for this study to gain information that would assist in obtaining biographical and health history of the participants. The contents included personal descriptive data such as age, gender, years 
of education, and income. Personal identification information that may breach confidentiality of participants was not be included. The inclusion of address was obtained separately to be able to send results of $\mathrm{HbA1C}$, if desired. Information was obtained on medical history, current pharmacological diabetes treatment, and whether treatment for depression was in progress. The medical history components is a list of nine illnesses commonly identified with type 2 diabetes where the response is in a dichotomous (yes/no) format with an option to write in additional illnesses not included in the list. All the participants were asked to report all the medications that they use on chronic basis. For the purpose of this manuscript, presence of ischemic heart disease and/or congestive heart failure and/or arrhythmia are referred to collectively as cardiac problems while the presence of any stage of chronic kidney disease is referred to as renal problems. The data reported by the participants regarding their medications was validated through checking the computerized system at the $\mathrm{MOH}$ which contained up-to-date information about the patients and their medications. The questionnaire was available in Arabic language.

\section{Data management and statistical analysis Pre-analysis}

During the pre-analysis phase, the data were coded to maintain confidentiality for all participants. Participants were given an identification number assigned by the PI for use throughout the study. In order to carry out quantitative statistical analysis, measurement for variables was established. Demographic information and summative score of the instruments was obtained as a continuous measure as much as possible to ease the process of designation measure according to statistical analysis. The data were entered onto an SPSS (Statistical Package for the Social Sciences) statistical software was used for data analysis.

\section{Statistical analyses}

Descriptive statistics was carried out for all variables and expressed as mean \pm SD for continuous variables with normal distribution. Non-normally distributed continuous variables were expressed as median (Q1-Q3). Normality of the data was tested by Kolomogrov-Smirnov test. Factors associated with depression scores $>16$ were analyzed with binary logistic regression followed by multiple logistic regression analysis. Variables that showed significance in univariate analysis were included in multiple logistic regression analysis. The dependent variable was depression scores $(\geq 16$ versus $<16)$. A p value of $<$ 0.05 was considered statistically significant.

\section{Protection of human subjects}

The study was undertaken as part of a higher research degree at An-Najah National University, Nablus, Palestine.
The study protocol was approved by the ethics committee called "Institutional Review Board" (IRB) of the college of Medicine and Health Sciences, Palestine. The application for ethics committee was submitted on May 01, 2012 and the approval was obtained on June 04, 2012. The interviewer explained the purpose of the study and procedures and gained written informed consent before commencing the interview. The participants were also informed that their participation was voluntary and that they could withdraw from the interview/study at any time without consequences. The participants were also informed about potential risks for participating in the study which were few and included any of the following: (1) becoming fatigued or nervous while completing the questionnaires, (2) possibility of pain to site during needle stick, (3) a hematoma at the venous puncture site, and/or (4) infection, although it is highly unlikely, from the needle stick. The participants were assured that their responses would be treated in confidence and they were assured anonymity through the use of strict coding measures. All information was kept confidential and consent forms were number coded for identification. The research file will be kept for five years after completion of the study. At the end of this period, records will be destroyed appropriately. The study was carried out in full compliance with the guidelines of good clinical practice of the world assembly declaration of Helsinki and was approved by the university ethical committee. Well informed consent was taken from all enrolled patients.

\section{Results}

During the study period, approximately 1400 patients visited the center and did the HbA1c test per required by the physician. Many of those patients leave the clinic immediately after taking the blood sample which made them un-available for interview. A net total of 301 diabetic patients were available and agreed to do the interview. Seven patients were excluded because of their inability to communicate or understand the questions or have sensory impairment like being deaf. A net of 294 type 2 diabetic patients met the inclusion criteria and were interviewed and their HbA1c test was obtained.

The majority $(216 ; 73.5 \%)$ of participants were younger than 65 years old. Age was negatively skewed with a median (Q1 - Q3) age of 60 (52 - 66.25) years. The majority $(164 ; 55.8 \%)$ of participants was female. The largest portion $(n=213,72.5 \%$ ) of participants reported being either illiterate or had a limited school education while those with college education were minority $(n=40$; $13.6 \%)$. The marital status as reported by participants was married ( $\mathrm{n}=243 ; 82.7 \%)$, single/divorced/widowed ( $n=51,17.3 \%)$. A small proportion $(n=62,21.1 \%)$ of the participants reported that they have a current job. The majority $(n=223,75.9 \%)$ of participants were non- 
smokers at the time of the study. Participants reported the number of years since diagnosis with type 2 diabetes which showed a wide distribution ranging from 5 - 35 years, positive skewness with a median (Q1 - Q3) of $10(5-16)$ years. The Body Mass Index (BMI) of the participants showed positive skewness with a median (Q1 - Q3) of 30.6 (27.2 - 35.1). The BMI for males was 28.8 (26.6 - 33.8) while that for females was $32(28.3-37.4)$. The difference in BMI between males and females was significant $(\mathrm{P}<$ 0.01 ) with a $Z$ score of -3.44 . More than half (166; $56.5 \%)$ of the participants had a $\mathrm{BMI} \geq 30$. Both systolic and diastolic blood pressures (SBP, DBP) showed positive skewness. The median (Q1 - Q3) values for SBP and DBP were $132(120-143)$ and $80(75-88) \mathrm{mmHg}$ respectively.

The number of diabetes medications reported by participants ranged from 0-3 types with a median $(\mathrm{Q} 1-\mathrm{Q} 3)$ of $2(1-2)$ medications. One hundred and forty seven (50\%) reported insulin use either as a monotherapy or in combination with other medications for diabetes management. Two hundred and sixty participants acknowledged having additional illnesses along with diabetes. The number of additional illnesses ranged from $1-5$ with a median (Q1 - Q3) of $2(1$ - 3). The most common chronic illness reported by the participants was high cholesterol $(\mathrm{n}=219,74.5 \%)$, followed by hypertension $(\mathrm{n}=178,60.5 \%)$, cardiac problems $(\mathrm{n}=84,28.6 \%)$ and renal problems $(37,12.6 \%)$. In the reported medical history, none of the participants recalled being informed that they had depression. Additionally, none of the participants reported taking medications for depression.

The results for $\mathrm{HbA} 1 \mathrm{C}$ ranged from 5.2 to $13 \%$, a median (Q1 - Q3) of 8.2\% (7.2 - 9.1). The median and mean scores of $\mathrm{HbA} 1 \mathrm{C}$ exceed the recommendation of $<7.0 \%$ established by the ADA [29]. The results were un-equally distributed with 3 extreme scores representing $\mathrm{HbA} 1 \mathrm{C}$ between 12 and 13\%. The HbA1C results were further divided into two categories: controlled $(<7 \%)$ and uncontrolled $(\geq 7.0 \%)$. The percentage of participants who had a controlled glucose was $17.7 \%(n=52)$. However, $82.3 \%(n=242)$ were in the uncontrolled level which places individuals at a greater risk for developing diabetic complication.

The depression symptoms score distribution was positively skewed with the majority of participants $[n=174$, $59.2 \%$ ] scored less than 16 while 120 (40.2\%) patients scored $\geq 16$ in the depression scale. Medication adherence scores were negatively skewed. The median value for medication adherence scores was $5.8(4.8-6.8)$. The majority $(\mathrm{n}=167,56.8 \%)$ of the participants had low adherence scores (MMAS- $8<6$ ). Table 1 shows univariate analysis of demographic and clinical factors with depression scores. The analysis showed that female diabetic patients, low level of education, having no current job, having higher number of additional illness, low medication adherence score and having high BMI were significantly associated with depression score of $\geq 16$. Multivariate analysis (Table 2) showed that: 1) diabetic patients with college education were less likely to have depression $[O . R=0.24 ;(0.09-0.66)]$ than those with lesser level of education, 2) diabetic patients with no current job were more likely to have depression $[\mathrm{O} . \mathrm{R}=2.78(1.23-6.27)$ ] than those who are currently working, 3) diabetic patients with multiple additional illnesses were more likely to have depression $[\mathrm{O} . \mathrm{R}=1.81(1.05-3.11)]$ than those with $\leq 1$ additional illness, and finally 4) diabetic patients with high medication adherence score were less likely to have depression $[\mathrm{O} . \mathrm{R}=0.31(0.18-0.53)]$ than those with low $(<6)$ medication adherence score.

\section{Discussion}

This study investigated the prevalence of depression among adult Palestinian type II diabetic patients and identified demographic and disease-related risk factors for depression. Our study showed that $40 \%$ of the screened patients are potential cases of depression. It should be emphasized that high BDI II scores presented in this study are not diagnostic of depression. Rather, high scores are indicative of the presence of depressive symptoms and further clinical consultation to establish definitive diagnosis of depression is needed. In our study, most patients who are potential cases of depression were females, had multiple additional illnesses, currently jobless, had low educational level, had low medication adherence, and had an abnormally high BMI. However, multivariate analysis showed that the only significant predictors of depression were low education, having no current job, having multiple additional illnesses, and having low medication adherence. Many research groups have investigated the relationship between diabetes mellitus and depression. Some research groups indicated that depression is highly prevalent among diabetics and the risk of depression might be increased in the presence of other co-morbid conditions [11,32-38]. Compared to other published studies, our results reported higher prevalence rate of depression among diabetics. A metaanalysis of 42 published studies found that the prevalence of major depression among diabetic patients was $11 \%$ and the prevalence of clinically serious depression was $31 \%$ [39]. A study in Jordan found that the prevalence rate of undiagnosed depression among Jordanian diabetic patients was $19.7 \%$ [17]. A meta-analysis study held in the United States found that the prevalence rate of depression among adult diabetic patients ranging from $3.8 \%$ to $27.3 \%$ [39]. Other studies reported a prevalence rates of $5.4 \%$ [40], 8\% [41], 32.4\% [42] and $41.3 \%$ [43]. One possible reason for the differences in the prevalence of depression among diabetic patients reported by different studies is the use of different scales 
Table 1 Univariate analysis of factors associated with depression

\begin{tabular}{|c|c|c|c|c|c|}
\hline \multirow[t]{3}{*}{ Variable } & \multirow{3}{*}{$\begin{array}{c}\text { Total } \\
\mathrm{N}=294\end{array}$} & \multicolumn{2}{|c|}{ BDI-II depression score } & \multirow{3}{*}{$\begin{array}{l}\text { Unadjusted OR } \\
\qquad(95 \% \mathrm{Cl})\end{array}$} & \multirow[t]{3}{*}{ P-value } \\
\hline & & $\geq 16$ & $<16$ & & \\
\hline & & $N=120$ & $N=174$ & & \\
\hline \multicolumn{6}{|l|}{ Age (years) } \\
\hline$\leq 65$ & $216(73.5 \%)$ & 85 (39.4\%) & $131(60.6 \%)$ & $0.8(0.5-1.3)$ & 0.40 \\
\hline$>65$ & $78(26.5 \%)$ & $35(44.9 \%)$ & $43(55.1 \%)$ & Reference & \\
\hline \multicolumn{6}{|l|}{ Gender } \\
\hline Male & $130(44.2 \%)$ & $43(33.1 \%)$ & $87(66.9 \%)$ & Reference & 0.02 \\
\hline Female & $164(55.8 \%)$ & $77(47.0 \%)$ & 87 (53.0\%) & $1.8(1.1-2.9)$ & \\
\hline \multicolumn{6}{|l|}{ Education } \\
\hline Illiterate & 87 (29.6\%) & $47(39.2 \%)$ & $40(23.0 \%)$ & Reference & \\
\hline Elementary & $126(42.9 \%)$ & $53(44.2 \%)$ & $73(42.0 \%)$ & $0.6(0.4-1.1)$ & 0.08 \\
\hline High school & 41 (13.9\%) & $13(10.80 \%)$ & $28(16.1 \%)$ & $0.4(0.2-0.9)$ & 0.02 \\
\hline College & $40(13.6 \%)$ & $7(5.8 \%)$ & $33(19.0 \%)$ & $0.2(0.1-0.5)$ & $<0.01$ \\
\hline \multicolumn{6}{|l|}{ Marital status } \\
\hline Married & $243(82.7 \%)$ & $101(41.6 \%)$ & $142(58.4 \%)$ & $1.2(0.6-2.2)$ & 0.58 \\
\hline Others & $51(17.3 \%)$ & $19(37.3 \%)$ & $32(62.7 \%)$ & Reference & \\
\hline \multicolumn{6}{|l|}{ Currently smoking } \\
\hline Yes & $71(24.1 \%)$ & $32(45.1 \%)$ & $39(54.9 \%)$ & $1.3(0.7-2.2)$ & 0.40 \\
\hline No & $166(56.5 \%)$ & $79(47.6 \%)$ & $84(52.4 \%)$ & Reference & \\
\hline \multicolumn{6}{|l|}{ Working } \\
\hline Yes & $62(21.1 \%)$ & $12(19.4 \%)$ & $50(80.6 \%)$ & Reference & $<0.01$ \\
\hline No & $232(78.9 \%)$ & $108(46.6 \%)$ & $124(53.4 \%)$ & $3.6(1.8-7.7)$ & \\
\hline Duration of illness & $10(5-16)$ & $12(6-16.75)$ & $10(5-15)$ & $1.0(0.9-1.05)$ & 0.32 \\
\hline \multicolumn{6}{|c|}{ Number of additional illness } \\
\hline$\leq 1$ & $114(38.8 \%)$ & $36(31.6 \%)$ & $78(68.4 \%)$ & Reference & 0.01 \\
\hline$\geq 2$ & $180(61.2 \%)$ & $84(46.9 \%)$ & $96(53.3 \%)$ & $1.9(1.2-3.1)$ & \\
\hline \multicolumn{6}{|c|}{ Number of anti-diabetic medication } \\
\hline$\leq 1$ & $112(38.1 \%)$ & $44(39.3 \%)$ & $68(60.7 \%)$ & Reference & 0.68 \\
\hline$\geq 2$ & $182(61.9 \%)$ & $76(41.8 \%)$ & $106(58.2 \%)$ & $1.1(0.7-1.8)$ & \\
\hline \multicolumn{6}{|l|}{ Insulin use } \\
\hline Yes & $147(50 \%)$ & $64(43.5 \%)$ & $83(56.5 \%)$ & $1.25(0.8-2.0)$ & 0.34 \\
\hline No & $147(50 \%)$ & $56(38.1 \%)$ & $91(61.9 \%)$ & Reference & \\
\hline \multicolumn{6}{|l|}{$\mathrm{HbA1C}$} \\
\hline$<7$ & $52(17.7 \%)$ & $23(44.2 \%)$ & $29(55.8 \%)$ & Reference & 0.58 \\
\hline$\geq 7$ & $242(82.3 \%)$ & $97(40.1 \%)$ & $145(59.9 \%)$ & $0.8(0.5-1.5)$ & \\
\hline \multicolumn{6}{|c|}{ Medication adherence score } \\
\hline$<6$ & $167(56.8 \%)$ & $86(51.5 \%)$ & $81(48.5 \%)$ & Reference & $<0.01$ \\
\hline$\geq 6$ & $127(43.2 \%)$ & $34(26.8 \%)$ & $91(73.2 \%)$ & $0.3(0.2-0.6)$ & \\
\hline \multicolumn{6}{|l|}{ BMI } \\
\hline$<25$ & $30(10.2 \%)$ & $7(23.3 \%)$ & $23(76.7 \%)$ & Reference & \\
\hline $25-29$ & $98(33.3 \%)$ & $34(34.7 \%)$ & $64(65.3 \%)$ & $1.8(0.7-4.5)$ & 0.25 \\
\hline$\geq 30$ & $166(56.5 \%)$ & $79(47.6 \%)$ & $84(52.4 \%)$ & $3.0(1.2-7.3)$ & 0.02 \\
\hline
\end{tabular}

Abbreviations: Cl confidence interval, BDI-II Beck Depression Inventory - Second edition, BMI Body Mass Index, MMAS-8 Morisky Medication Adherence Scale-8 items, OR Odds Ratio, HbA1C Glycated Hemoglobin. 
Table 2 Multivariate analysis of factors associated with depression

\begin{tabular}{|c|c|c|c|c|c|c|}
\hline Variables & & $\beta$ & S.E. & Wald & p-value & Odds ratio with $95 \% \mathrm{Cl}$ \\
\hline \multirow[t]{2}{*}{ Gender } & Female & & & & & Reference \\
\hline & Male & -0.04 & 0.31 & 0.02 & 0.898 & $0.96(0.52-1.77)$ \\
\hline \multirow[t]{4}{*}{ Education } & Illiterate & & & & & Reference \\
\hline & Elementary & -0.33 & 0.31 & 1.15 & 0.284 & $0.72(0.39-0.32)$ \\
\hline & High school & -0.85 & 0.45 & 3.61 & 0.057 & $0.43(0.18-1.03)$ \\
\hline & College & -1.42 & 0.52 & 7.57 & 0.006 & $0.24(0.09-0.66)$ \\
\hline \multirow[t]{2}{*}{ Occupation } & Yes & & & & & Reference \\
\hline & No & 1.02 & 0.42 & 6.05 & 0.014 & $2.78(1.23-6.27)$ \\
\hline \multirow[t]{2}{*}{ Additional illness } & $\leq 1$ & & & & & Reference \\
\hline & $\geq 2$ & 0.59 & 0.28 & 4.55 & 0.033 & $1.81(1.05-3.11)$ \\
\hline \multirow[t]{3}{*}{ BMI } & $<25$ & & & & & Reference \\
\hline & $25-<30$ & 0.50 & 0.52 & 0.92 & 0.336 & $1.65(0.60-4.58)$ \\
\hline & $\geq 30$ & 0.86 & 0.50 & 3.00 & 0.083 & $2.36(0.90-6.23)$ \\
\hline \multirow[t]{2}{*}{ Medication adherence score } & $<6$ & & & & & Reference \\
\hline & $\geq 6$ & -1.17 & 0.27 & 14.17 & 0.001 & $0.31(0.18-0.53)$ \\
\hline
\end{tabular}

Abbreviations: $\mathrm{Cl}$ confidence interval, $\beta$ coefficient of predictor variables, BMI Body Mass Index, MMAS-8 Morisky Medication Adherence Scale-8 items,

OR Odds Ratio.

used to screen for depressive symptoms. Some studies used the PHQ-8, others used Ham-D or BDI II scales.

The increased vulnerability to depression in individuals with type 2 diabetes is not yet clearly understood. However, depression involves physiological changes of the neuroendocrine system. The underlying cause of depression is thought to be related to changes in the neurotransmitters in the brain such as serotonin (5-HT), dopamine (DA), and norepinephrine (NE) which are monoamine neurotransmitters which affect mood and behavior. It is believed that during psychological stress counter regulatory hormones such as catecholamine a neurotransmitter, glucocorticoids, growth hormones, and glucagons are activated [44]. The activation of the counter regulatory hormones interferes in the action of insulin which is not able to lower glucose but instead elevates blood glucose. The increase in glucose level creates a greater challenge in maintaining metabolic control. Poor glycemic control and functional impairment due to increasing diabetes complications may cause or worsen depression and lessen the response to antidepressant treatment [45]. In spite of the known devastating effect of depression on diabetes, it was found that only $31 \%$ of patients with diabetes and depression received adequate antidepressant treatment and only 6\% received 4-5 sessions of psychotherapy in a 12 month period [46]. Studies of the economics of treatment of depression among diabetic patients have yielded positive results. The health care expenses sustained by individuals with diabetes and depression are higher than those with diabetes alone $[47,48]$.

It may be argued that the high prevalence rate of depression found in our study is due to many patients having uncontrolled diabetes (82\%). However, we did not find significant relationship between glycemic control and potential for depression. Studies about the relationship between depression and poor glycemic control gave mixed results. A study had shown a negative relationship between depression and poor glycemic control and diabetes complications. Worse glycemic control was observed in depressed adults with diabetes [49]. A metaanalysis study [50] found that patients with type 1 and type 2 diabetes and depression persistently had higher HbA1c levels [50]. Wagner et al. also found higher HbA1c and more diabetes complications in African Americans with higher depressive symptoms after controlling for confounders between depression and HbA1c levels [51]. In a prospective representative study of patients with type 2 diabetes, depression predicted problems with medication adherence, and unsatisfactory glycemic control [52]. Diabetic complications and mortality were also found to be greater among depressed patients [14,53,54]. The microvascular and macrovascular complications of diabetes are augmented by the presence of depression in diabetes thus contributing to the increased mortality rate in this population [55]. In contrast, other investigators found no relationship between depression and diabetic complications [42,56-58]. Crosssectional studies found a significant positive correlation between depressive symptoms and HbA1c in patients with Type 1 diabetes but no significant correlation in patients with Type 2 diabetes [59-61], indicating that depression affects glycemic control in patients with Type 1 but not Type 2 diabetes. In support of this, a study found that patients with Type 1 but not Type 2 diabetes 
who had depression showed significantly worse glycemic control than their counterparts who had no depression $[62,63]$. A study showed that changes in depressive symptoms were not associated with changes in HbA1c or fasting glucose levels over a 1-year period in either patients with Type 1 or Type 2 diabetes [63].

Our study showed that approximately two thirds of those who scored $\geq 16$ points were females. The higher prevalence of depression among females is in consistence with other studies $[17,35,55,64,65]$. In a metaanalysis, Anderson et al found that diabetes doubles the risk of depression and it is especially more among females [39]. However, not all studies reported this gender differences in depression [58]. Our results indicated that about $90 \%$ of the total sample was either overweight or obese (had a BMI > 25). The BDI score was significantly higher among obese patients. A study found that depression was more common among diabetic women especially if they were overweight and that body weight was a predictor of depression more than diabetes itself [66]. Similarly, recent studies have found that higher BMI was a predictor of depression in type 2diabetes [64,67]. High educational level decreases the odds of being classified as depressed patients which is similar to findings published in other studies [13,17]. Medication adherence showed a significant relationship with depression. Adherent patients are associated with lower odds of being depressed. It has been reported by other researchers that depressed diabetic patients do not pay much effort on daily management activities [68,69] and this result is consistent with many studies that reported that depressed diabetic patients are likely to have physical limitations and a poor quality of life [70-73], bearing in mind that self-care behaviors in diabetes include adherence to dietary restrictions and medications, adequate physical exercise and blood glucose monitoring $[68,69]$. Management guidelines for diabetes mellitus emphasize the importance of medication adherence, physical activity, diet and self-monitoring of blood glucose [74]. Gonzalez et al. proposed that the presence of depressive symptoms are good predictors of poor adherence to selfcare particularly in adherence to medications and diet and exercise regimens [75]. A systematic review of treatment adherence among individuals with diabetes and depression indicated that there was a significant relationship between depression and treatment nonadherence [75]. Finally, our study indicated that having no work is significantly associated with depression score $\geq 16$ points. This is expected since having no work is by itself a depressing factor.

In contrast to some other studies, our study showed no significant association between depression score and age among diabetic patients [76]. Furthermore, our study showed no significant association between depression and the use of insulin which is contrary to other published studies [11]. A study reported that delayed initiation of insulin in type 2 makes a significant number of diabetic patients vulnerable to diabetic complications and its adverse outcomes, including depression [77]. Our study found that the duration of DM was not significantly associated with depression which is consistent with the findings reported by other studies [78,79]. However, because the incidence of diabetic complication increases with increased illness duration, one could expect greater depression risk in those who have been ill for a longer time. Some research groups reported a significantly higher rate of depression in individual with long standing history of diabetes than in the newly diagnosed diabetic [80].

Our study is the first to be conducted in Palestine to determine the prevalence of undiagnosed depression among diabetic patients. However, our study has few limitations. First, this study is cross-sectional where causal relationship between diabetes and depression cannot be established. Variables identified as significantly associated with depression may precede depression, but in some cases, these variables could also occur as a result of depression; thus, high scores of BDI II among diabetic patients must be interpreted with caution. Further studies with longitudinal prospective design and the presence of age and gender matched group is needed to shed more light on the potential relationship between depression and diabetes mellitus. It is important to state that depression screening measures provide an estimation of the severity of depressive symptoms and assess the severity within a specific period of time but they do not diagnose depression. However, those who score high in depression measure scales need to interviewed and assessed for a confirmation of depression. The second limitation of this study was its partial reliance on self-report for its measures, including depression and medication adherence; therefore, a clinical interview to assess depression maybe a superior measure because of its higher level of specificity. Accordingly, a longitudinal clinical study of a community-based sample using clinical symptoms for diagnosis of depression is needed to assess the relationship between various variables including diabetes control. Third limitation of this study was HbAlc measurement. The presence of many clinically silent hemoglobin variants might cause deviation in the HbA1c results leading to falsely high or low values $[81,82]$. Therefore, the accuracy of the results and validity of the HbA1c interpretation cannot be assured. Finally, gender differences in risk of depression among diabetic patients need further investigation using large sample size is needed since univariate analysis showed such gender differences with higher risk among females. Community-based study among diabetic women will be of great value given that women are more prone to depression than men. 


\section{Conclusion}

The prevalence of depression among Palestinian diabetic patients is higher than reported in other communities and has never been approached before. Being a female, not adherent to anti-diabetic medications, having low educational level and being jobless were significant predictors and are associated with an increased likelihood of developing major depressive disorders. We highly recommend the introduction of the psychological aspect among the diabetic health care plan to reduce the number of the depressed or the misrecognized depressed diabetic patients and consequently offer them a better quality of life.

\section{Abbreviations}

BDI-II: Beck depression inventory - second edition; HbA1C: Glycated hemoglobin; MMAS-8: Morisky medication adherence scale - 8 items; IRB: Institutional review board; BMI: Body mass index; DM: Diabetes mellitus.

\section{Competing interests}

The authors declare that they have no competing interests.

\section{Authors' contributions}

All authors were involved in drafting the article and all authors approved the final version to be submitted for publication. All authors have added an intellectual significant value to the manuscript. H.A was involved in subject recruitment and interview, data collection, data coding and entry, literature review, and manuscript editing. This was done in partial fulfillment of a master degree in Community Mental Health Nursing at An-Najah National University. S.A and S.Z were involved in concept, study design, manuscript writing and editing, and academic co-supervision for H.A according to An-Najah university regulations. W.S was involved in the study conception and design, literature review, manuscript writing, manuscript submission, manuscript revision, head of the research group, and academic supervision for H.A according to An-Najah university regulations. This manuscript is part of a project for master degree in the graduate program of Community Mental Health Nursing. The project was initially and originally conceptualized and designed by the Clinical Pharmacology/ Toxicology Research Group at An-Najah National University (W.S, S.Z, and S.A). The project was then assigned to H.A as a thesis project and was academically supervised by W.S and S.A in adherence to An-Najah University regulations with regard to academic supervision for graduate students.

\section{Authors' information}

Professor Waleed M. Sweileh is the head of a research group (S.Z, S.A, A.S and A.A) which has published in the field of clinical pharmacology, toxicology, pharmacoepidemiology, social and community pharmacy, clinical pharmacy and medicine. The research group has also supervised many students in the fields of nursing, public health and pharmacy.

\section{Acknowledgment}

The authors would like to express many thanks and gratitude to the Dean of Graduate Studies at An-Najah University and the Palestinian $\mathrm{MOH}$ for their help and ethical approval to conduct this study.

\section{Author details}

${ }^{1}$ Department of Pharmacology/ Toxicology, College of Medicine and Health Sciences, An-Najah National University, Nablus, Palestine. ${ }^{2}$ Qalqilia Governmental Hospital, Ministry of Health, Qalqilia, Palestine. ${ }^{3}$ Department of Clinical and Comunity Pharmacy, College of Medicine and Health Sciences, An-Najah National University, Nablus, Palestine.

Received: 28 June 2013 Accepted: 11 February 2014

Published: 13 February 2014

\section{References}

1. Shaw JE, Sicree RA, Zimmet PZ: Global estimates of the prevalence of diabetes for 2010 and 2030. Diabetes Res Clin Pract 2010, 87(1):4-14.
2. Abdul-Rahim HF, Husseini A, Giacaman R, Jervell J, Bjertness E: Diabetes mellitus in an urban Palestinian population: prevalence and associated factors. East Mediterr Health J 2001, 7(1-2):67-78.

3. Husseini A, Abdul-Rahim H, Awartani F, Jervell J, Bjertness E: Prevalence of diabetes mellitus and impaired glucose tolerance in a rural Palestinian population. East Mediterr Health J 2000, 6(5-6):1039-1045.

4. Husseini A, Abdul-Rahim H, Awartani F, Giacaman R, Jervell J, Bjertness E: Type 2 diabetes mellitus, impaired glucose tolerance and associated factors in a rural Palestinian village. Diabet Med 2000, 17(10):746-748.

5. Husseini A, Abu-Rmeileh NM, Mikki N, Ramahi TM, Ghosh HA, Barghuthi N, Khalili M, Bjertness E, Holmboe-Ottesen G, Jervell J: Cardiovascular diseases, diabetes mellitus, and cancer in the occupied Palestinian territory. Lancet 2009, 373(9668):1041-1049.

6. Greden JF: Physical symptoms of depression: unmet needs. J Clin Psychiatry 2003, 64(Suppl 7):5-11.

7. Demyttenaere K, Bruffaerts R, Posada-Villa J, Gasquet I, Kovess V, Lepine JP Angermeyer MC, Bernert S, de Girolamo G, Morosini P, et al: Prevalence, severity, and unmet need for treatment of mental disorders in the world health organization world mental health surveys. JAMA 2004, 291(21):2581-2590.

8. Meyer C: Depressive disorders were the fourth leading cause of global disease burden in the year 2000. Evid Based Ment Health 2004, 7(4):123.

9. Ustun TB, Ayuso-Mateos JL, Chatterji S, Mathers C, Murray CJ: Global burden of depressive disorders in the year 2000. Br J Psychiatry 2004, 184:386-392.

10. Michaud CM, Murray CJ, Bloom BR: Burden of disease-implications for future research. JAMA 2001, 285(5):535-539.

11. Li C, Ford ES, Strine TW, Mokdad AH: Prevalence of depression among U.S. adults with diabetes: findings from the 2006 behavioral risk factor surveillance system. Diabetes Care 2008, 31(1):105-107.

12. Ali S, Stone MA, Peters $J$, Davies MJ, Khunti K: The prevalence of co-morbid depression in adults with Type 2 diabetes: a systematic review and meta-analysis. Diabet Med 2006, 23(11):1165-1173.

13. Katon W, Von Korff M, Ciechanowski P, Russo J, Lin E, Simon G, Ludman E, Walker E, Bush T, Young B: Behavioral and clinical factors associated with depression among individuals with diabetes. Diabetes Care 2004, 27(4):914-920

14. Katon WJ, Simon G, Russo J, Von Korff M, Lin EHB, Ludman E, Ciechanowski P, Bush T: Quality of depression care in a population-based sample of patients with diabetes and major depression. Med Care 2004, 42(12):1222-1229.

15. Giacaman R, Khatib R, Shabaneh L, Ramlawi A, Sabri B, Sabatinelli G, Khawaja M, Laurance T: Health status and health services in the occupied Palestinian territory. Lancet 2009, 373(9666):837-849.

16. Palestinian Ministry of Health: Health Status in Palestine 2011. 2011. http:// www.moh.ps/attach/441.pdf. Accessed 30 January 2013

17. Al-Amer RM, Sobeh MM, Zayed AA, Al-Domi HA: Depression among adults with diabetes in Jordan: risk factors and relationship to blood sugar control. J Diabetes Complications 2011, 25(4):247-252.

18. Beck AT, Steer RA, Brown GK: Manual for Beck Depression Inventory-II. San Antonio, TX: Psychological Corporation; 1996.

19. Beck AT, Guth D, Steer RA, Ball R: Screening for major depression disorders in medical inpatients with the Beck Depression Inventory for Primary Care. Behav Res Ther 1997, 35(8):785-791.

20. Steer RA, Ball R, Ranieri WF, Beck AT: Further evidence for the construct validity of the Beck depression Inventory-II with psychiatric outpatients. Psychol Rep 1997, 80(2):443-446.

21. Steer RA, Ball R, Ranieri WF, Beck AT: Dimensions of the Beck Depression Inventory-II in clinically depressed outpatients. J Clin Psychol 1999, 55(1):117-128.

22. Steer RA, Cavalieri TA, Leonard DM, Beck AT: Use of the Beck Depression Inventory for Primary Care to screen for major depression disorders. Gen Hosp Psychiatry 1999, 21(2):106-111.

23. Steer RA, Clark DA, Beck AT, Ranieri WF: Common and specific dimensions of self-reported anxiety and depression: the BDI-II versus the BDI-IA. Behav Res Ther 1999, 37(2):183-190.

24. Steer RA, Rissmiller DJ, Beck AT: Use of the beck depression inventory-II with depressed geriatric inpatients. Behav Res Ther 2000, 38(3):311-318.

25. Winter LB, Steer RA, Jones-Hicks L, Beck AT: Screening for major depression disorders in adolescent medical outpatients with the beck depression inventory for primary care. J Adolesc Health 1999, 24(6):389-394. 
26. Alansari BM: Beck Depression Inventory (BDI-II) items characteristics among undergraduate students of nineteen Islamic countries. Soc Behav Pers 2005, 33(7):675-684.

27. Alansari BM: Gender differences in depression among undergraduates from seventeen Islamic countries. Soc Behav Person 2006, 34(6):729-738.

28. Lustman PJ, Clouse RE, Griffith LS, Carney RM, Freedland KE: Screening for depression in diabetes using the beck depression inventory. Psychosom Med 1997, 59(1):24-31.

29. American Diabetes Association: Standards of medical care in diabetes-2010. Diabetes Care 2010, 33 Suppl 1:S11-61.

30. Morisky DE, Green LW, Levine DM: Concurrent and predictive validity of a self-reported measure of medication adherence. Med Care 1986, 24(1):67-74.

31. Jamous RM, Sweileh WM, Abu-Taha AS, Sawalha AF, Zyoud SH, Morisky DE: Adherence and satisfaction with oral hypoglycemic medications: a pilot study in Palestine. Int J Clin Pharm 2011, 33(6):942-948.

32. Pibernik-Okanovic M, Peros K, Szabo S, Begic D, Metelko Z: Depression in Croatian Type 2 diabetic patients: prevalence and risk factors. A Croatian survey from the European Depression in Diabetes (EDID) Research Consortium. Diabet Med 2005, 22(7):942-945.

33. Chou KL, Chi I: Prevalence of depression among elderly Chinese with diabetes. Int J Geriatr Psychiatry 2005, 20(6):570-575.

34. Ali S, Davies MJ, Taub NA, Stone MA, Khunti K: Prevalence of diagnosed depression in South Asian and white European people with type 1 and type 2 diabetes mellitus in a UK secondary care population. Postgrad Med J 2009, 85(1003):238-243.

35. Asghar S, Hussain A, Ali SM, Khan AK, Magnusson A: Prevalence of depression and diabetes: a population-based study from rural Bangladesh. Diabet Med 2007, 24(8):872-877.

36. Pouwer F, Geelhoed-Duijvestijn PH, Tack CJ, Bazelmans E, Beekman AJ, Heine RJ, Snoek FJ: Prevalence of comorbid depression is high in out-patients with Type 1 or Type 2 diabetes mellitus. Results from three out-patient clinics in the Netherlands. Diabet Med 2010, 27(2):217-224.

37. Engum A, Mykletun A, Midthjell K, Holen A, Dahl AA: Depression and diabetes: a large population-based study of sociodemographic, lifestyle, and clinical factors associated with depression in type 1 and type 2 diabetes. Diabetes Care 2005, 28(8):1904-1909.

38. Mezuk B, Eaton WW, Albrecht S, Golden SH: Depression and type 2 diabetes over the lifespan: a meta-analysis. Diabetes Care 2008, 31(12):2383-2390.

39. Anderson RJ, Freedland KE, Clouse RE, Lustman PJ: The prevalence of comorbid depression in adults with diabetes: a meta-analysis. Diabetes Care 2001, 24(6):1069-1078.

40. Zahid N, Asghar S, Claussen B, Hussain A: Depression and diabetes in a rural community in Pakistan. Diabetes Res Clin Pract 2008, 79(1):124-127.

41. Lloyd CE, Dyer PH, Barnett AH: Prevalence of symptoms of depression and anxiety in a diabetes clinic population. Diabet Med 2000, 17(3):198-202.

42. Bailey BJ: Mediators of depression in adults with diabetes. Clin Nurs Res 1996, 5(1):28-42.

43. Rubin RT, Poland RE, Lesser IM, Winston RA, Blodgett AL: Neuroendocrine aspects of primary endogenous depression. I. Cortisol secretory dynamics in patients and matched controls. Arch Gen Psychiatry 1987, 44(4):328-336

44. Grisel JE, Rasmussen PR, Sperry L: Anxiety and depression: physiological and pharmacological considerations. J Individ Psychol 2006, 62(4):398-416.

45. Lustman PJ, Clouse RE: Depression in diabetic patients: the relationship between mood and glycemic control. J Diabetes Complications 2005, 19(2):113-122.

46. Katon WJ: The comorbidity of diabetes mellitus and depression. Am J Med 2008, 121(11 Suppl 2):S8-15.

47. Ciechanowski PS, Katon WJ, Russo JE: Depression and diabetes: impact of depressive symptoms on adherence, function, and costs. Arch Intern Med 2000, 160(21):3278-3285.

48. Katon WJ, Rutter C, Simon G, Lin EH, Ludman E, Ciechanowski P, Kinder L, Young B, Von Korff M: The association of comorbid depression with mortality in patients with type 2 diabetes. Diabetes Care 2005, 28(11):2668-2672.

49. Sahota PKC, Knowler WC, Looker HC: Depression, diabetes, and glycemic control in an American Indian community. J Clin Psychiatry 2008, 69(5):800-809.
50. Lustman PJ, Anderson RJ, Freedland KE, de Groot M, Carney RM, Clouse RE: Depression and poor glycemic control: a meta-analytic review of the literature. Diabetes Care 2000, 23(7):934-942.

51. Wagner JA, Abbott GL, Heapy A, Yong L: Depressive symptoms and diabetes control in African Americans. J Immigr Minor Health 2009, 11(1):66-70

52. Dirmaier J, Watzke B, Koch U, Schulz H, Lehnert H, Pieper L, Wittchen HU: Diabetes in primary care: prospective associations between depression, nonadherence and glycemic control. Psychother Psychosom 2010, 79(3):172-178.

53. De Groot M, Anderson R, Freedland KE, Clouse RE, Lustman PJ: Association of depression and diabetes complications: a meta-analysis. Psychosom Med 2001, 63(4):619-630.

54. Egede LE: Effect of comorbid chronic diseases on prevalence and odds of depression in adults with diabetes. Psychosom Med 2005, 67(1):46-51.

55. Black SA, Markides KS, Ray LA: Depression predicts increased incidence of adverse health outcomes in older Mexican Americans with type 2 diabetes. Diabetes Care 2003, 26(10):2822-2828.

56. Winocour PH, Main CJ, Medlicott G, Anderson DC: A psychometric evaluation of adult patients with type 1 (insulin-dependent) diabetes mellitus: prevalence of psychological dysfunction and relationship to demographic variables, metabolic control and complications. Diabetes Res 1990, 14(4):171-176.

57. Viinamaki H, Niskanen L, Uusitupa M: Mental well-being in people with non-insulin-dependent diabetes. Acta Psychiatr Scand 1995, 92(5):392-397.

58. Peyrot M, Rubin RR: Levels and risks of depression and anxiety symptomatology among diabetic adults. Diabetes Care 1997, 20(4):585-590.

59. Surwit RS, van Tilburg MA, Parekh PI, Lane JD, Feinglos MN: Treatment regimen determines the relationship between depression and glycemic control. Diabetes Res Clin Pract 2005, 69(1):78-80.

60. Van Tilburg MA, McCaskill CC, Lane JD, Edwards CL, Bethel A, Feinglos MN, Surwit RS: Depressed mood is a factor in glycemic control in type 1 diabetes. Psychosom Med 2001, 63(4):551-555.

61. Ciechanowski PS, Katon WJ, Russo JE, Hirsch IB: The relationship of depressive symptoms to symptom reporting, self-care and glucose control in diabetes. Gen Hosp Psychiatry 2003, 25(4):246-252.

62. de Groot M, Jacobson AM, Samson JA, Welch G: Glycemic control and major depression in patients with type 1 and type 2 diabetes mellitus. J Psychosom Res 1999, 46(5):425-435.

63. Georgiades A, Zucker N, Friedman KE, Mosunic CJ, Applegate K, Lane JD, Feinglos MN, Surwit RS: Changes in depressive symptoms and glycemic control in diabetes mellitus. Psychosom Med 2007, 69(3):235-241.

64. de Groot M, Doyle T, Hockman E, Wheeler C, Pinkerman B, Shubrook J, Gotfried R, Schwartz F: Depression among type 2 diabetes rural Appalachian clinic attendees. Diabetes Care 2007, 30(6):1602-1604.

65. de Groot M, Pinkerman B, Wagner J, Hockman E: Depression treatment and satisfaction in a multicultural sample of type 1 and type 2 diabetic patients. Diabetes Care 2006, 29(3):549-553.

66. Nichols GA, Brown JB: Unadjusted and adjusted prevalence of diagnosed depression in type 2 diabetes. Diabetes Care 2003, 26(3):744-749.

67. Sacco WP, Wells KJ, Friedman A, Matthew R, Perez S, Vaughan CA: Adherence, body mass index, and depression in adults with type 2 diabetes: the mediational role of diabetes symptoms and self-efficacy. Health Psychol 2007, 26(6):693-700.

68. Lerman I, Lozano L, Villa AR, Hernandez-Jimenez S, Weinger K, Caballero AE, Salinas CA, Velasco ML, Gomez-Perez FJ, Rull JA: Psychosocial factors associated with poor diabetes self-care management in a specialized center in Mexico City. Biomed Pharmacother 2004, 58(10):566-570.

69. Park $H$, Hong $Y$, Lee $H, H a$ E, Sung $Y$ : Individuals with type 2 diabetes and depressive symptoms exhibited lower adherence with self-care. J Clin Epidemiol 2004, 57(9):978-984.

70. Finkelstein EA, Bray JW, Chen H, Larson MJ, Miller K, Tompkins C, Keme A, Manderscheid R: Prevalence and costs of major depression among elderly claimants with diabetes. Diabetes Care 2003, 26(2):415-420.

71. McCollum M, Ellis SL, Regensteiner JG, Zhang W, Sullivan PW: Minor depression and health status among US adults with diabetes mellitus. Am J Manag Care 2007, 13(2):65-72.

72. Brown GC, Brown MM, Sharma S, Brown H, Gozum M, Denton P: Quality of life associated with diabetes mellitus in an adult population. $J$ Diabetes Complications 2000, 14(1):18-24. 
73. Egede LE: Diabetes, major depression, and functional disability among US adults. Diabetes Care 2004, 27(2):421-428.

74. Egede LE: Effect of depression on self-management behaviors and health outcomes in adults with type 2 diabetes. Curr Diabetes Rev 2005, 1(3):235-243.

75. Gonzalez JS, Safren SA, Delahanty LM, Cagliero E, Wexler DJ, Meigs JB, Grant RW: Symptoms of depression prospectively predict poorer self-care in patients with Type 2 diabetes. Diabet Med 2008, 25(9):1102-1107.

76. Blazer DG, Moody-Ayers S, Craft-Morgan J, Burchett B: Depression in diabetes and obesity: racial/ethnic/gender issues in older adults. J Psychosom Res 2002, 53(4):913-916.

77. Phillips LS, Branch WT, Cook CB, Doyle JP, El-Kebbi IM, Gallina DL, Miller CD, Ziemer DC, Barnes CS: Clinical inertia. Ann Intern Med 2001, 135(9):825-834.

78. Karlson B, Agardh CD: Burden of illness, metabolic control, and complications in relation to depressive symptoms in IDDM patients. Diabet Med 1997, 14(12):1066-1072.

79. Miyaoka Y, Miyaoka H, Motomiya T, Kitamura S, Asai M: Impact of sociodemographic and diabetes-related characteristics on depressive state among non-insulin-dependent diabetic patients. Psychiatry Clin Neurosci 1997, 51(4):203-206.

80. Palinkas LA, Barrett-Connor E, Wingard DL: Type 2 diabetes and depressive symptoms in older adults: a population-based study. Diabet Med 1991 8(6):532-539.

81. Tsai L-Y, Tsai S-M, Lin M-N, Liu S-F: Effect of hemoglobin variants (Hb J, $\mathrm{Hb} \mathrm{G}$, and $\mathrm{Hb} \mathrm{E}$ ) on $\mathrm{HbA} 1 \mathrm{c}$ values as measured by cation-exchange HPLC (Diamat). Clin Chem 2001, 47(4):756-758.

82. Nasir NM, Thevarajah M, Yean CY: Hemoglobin variants detected by hemoglobin A1c (HbA1c) analysis and the effects on $\mathrm{HbA1c}$ measurements. Int J Diabetes Dev Ctries 2010, 30(2):86-90.

doi:10.1186/1471-2458-14-163

Cite this article as: Sweileh et al:: Prevalence of depression among people with type 2 diabetes mellitus: a cross sectional study in Palestine. BMC Public Health 2014 14:163.

\section{Submit your next manuscript to BioMed Central and take full advantage of:}

- Convenient online submission

- Thorough peer review

- No space constraints or color figure charges

- Immediate publication on acceptance

- Inclusion in PubMed, CAS, Scopus and Google Scholar

- Research which is freely available for redistribution 